\title{
People Engaging Each Other: A Dual-Perspective Study of Interpersonal Processes in Useful Therapy
}

\author{
Marit Råbu ${ }^{1}$ (1) Christian Moltu ${ }^{2,3}$
}

Published online: 29 July 2020

(c) The Author(s) 2020

\begin{abstract}
To explore how clients and therapists experience and engage in a therapeutic relationship which the client can make use of. We explored 11 psychotherapy dyads using in-depth qualitative methods. Selected dyads were ones in which the client experienced the therapy as useful. The data collection method was serial interviews with both therapists and clients. Therapists and clients were interviewed separately, four and two times, respectively, about their personal development, their views on and experiences with therapy, and their collaboration in the concrete therapeutic dyad. Transcripts of interviews were analyzed using a hermeneutic phenomenological qualitative analysis. The analysis yielded an overarching theme identified as "engaging each other." This theme consisted of three constituent processes, developed from complementary descriptions from clients and therapists: (1) opening up to an encounter between humans, (2) trusting professionality, and (3) creating space for an unbearable story. We discuss how technical skill and personal warmth underlie the development of a helping relationship within which humans can open up to a personal encounter with suffering. We discuss how the personal aspect of the therapist position relates to psychotherapy as a moral practice, and suggest that this perspective is meaningful in understanding the therapist factor and the real relationship.
\end{abstract}

Keywords Alliance $\cdot$ Authenticity $\cdot$ Clinical encounter $\cdot$ Qualitative method

In a recent meta-analysis of qualitative studies of alliance formation from client and therapist perspectives, Lavik et al. (2018a) concluded that clients express needs for therapists who are competent professionally to provide problem-solving strengths and hope, while also helping in overcoming initial fears and apprehension with personal warmth and tolerance. Therapists in this meta-analysis emphasized that they worked continuously to combine technical interventions with interpersonal warmth. It seems the tripartite formulation (Bordin 1979) of the alliance, including agreement on goals and tasks, and developing an emotional bond, encompasses many key therapeutic experiences and activities from the perspectives of both the client and the therapist.

Marit Råbu

mariraa@psykologi.uio.no

1 Department of Psychology, University of Oslo, Oslo, Norway

2 Department of Psychiatry, District General Hospital of Førde, Førde, Norway

3 Department of Health and Caring Sciences, Western Norway University of Applied Sciences, Førde, Norway
Charles Gelso has contributed significant work to the field of psychotherapy research in synthesizing, developing, and refining the construct of the real relationship, occurring alongside transference dynamics in psychotherapy (Gelso $2009,2011)$. Beyond what traditionally goes into its sister construct the alliance (Gelso 2014), the real relationship focuses on genuineness and realism, and covers interpersonal and existential ground. Evoking an insight offered by Freud (1937), the concept also suggests that relational experiences occur in therapy processes that are true and authentic in the here and now, rather than enactments or transferencedynamics coming from clients' or therapists' object relationships. In a recent meta-analysis of 16 studies, Gelso et al. (2018a, b) reported a moderate association between a measure of the real relationship and outcome. When magnitude of realism and genuineness in psychotherapy processes affect outcome, this brings the person of the therapist, often called the therapist effect (Anderson et al. 2009; Soldz 2006), into the discussion. How does genuineness go into the interpersonal processes of therapeutic relationship formation?

It seems established that the person of the therapist plays an important role in how psychotherapy processes develop 
(Baldwin and Imel 2013; Duncan 2014; Johns et al. 2019). We have less knowledge about how these aspects are played out in actual practice. Research into individual qualities of psychotherapists, beyond formal training and treatment modality, has grown since Ackermann and Hilsenroth (2003) reviewed therapist characteristics associated with good practice. This line of research is particularly motivated by studies demonstrating that therapists differ significantly from one client to another with regard to the outcome they achieve, even when they have similar formal training and experience (Kraus et al. 2011; Okiishi et al. 2003). Studies into the therapist beyond the formal role include, for example, Nissen-Lie et al. (2013), demonstrating that therapist's relational functioning is linked to obtained outcomes with patients. Moreover, Nissen-Lie et al. (2017) reported that the mix of professional self-doubt and personal self-affiliation in therapists was positively associated with outcome. A recent qualitative meta-analysis reported that therapists who could be open and immediate facilitated constructive therapeutic processes (Hill et al. 2018). In an in-depth study of helpful therapists, Bernhardt et al. (2019) detailed how the therapists experienced therapeutic practice as a place where they carried with them personal vulnerabilities and development into integration with the professional stance for each individual patient. Moltu et al. (2010) studied experienced therapists and described how they evoked a range of personal experiences to regulate and create hope within themselves in difficult therapeutic impasses.

However, the therapist is not the only person in the room who is a full human being. Research on client contributions to therapy effects and suggestions that "it is the client [...] that makes therapy work" (Tallman and Bohart 1999, p. 91) demonstrate that it indeed takes two to tango, and that in psychotherapy both can lead. This approach studies how clients, beyond their problems or diagnoses, actively contribute to therapy processes. For example, Rhodes et al. (1994) studied 19 cases of misunderstanding events, and showed how clients assert themselves and entered into mutual repair processes in contexts of a good relationship, stating that this processing of a misunderstanding event "made the relationship more real and human-like" (p. 478). Rennie (2000) studied client perspectives using interpersonal process recall and reported that they actively lead therapeutic conversations to pursue their goals. Moltu et al. (2012) studied experienced therapists' perspective of difficult therapy processes and found that they perceived progress as coming from clients' acts of courage and constructive interpersonal transgression. In summary, the client's relational capacity and motivation, beyond what is problematic or diagnostic, seems one important part of the therapeutic potential.

A few single case studies have explored psychotherapy with the dyad as the research focus, where experiences and personhood of both therapist and client are studied in depth over time in the context of a concrete therapy process (Halvorsen et al. 2016; Råbu et al. 2010, 2011). To focus on the dyad and both parties' experiences in the context of a psychotherapy process seems important, in that dyadic and creative processes such as psychotherapy can result in something other than, or greater than, the sum of its parts. However, its parts are what is most often studied in retrospective qualitative studies. Aiming to expand on this approach, in the current study we explore the research question in a dyadic study: How do clients and therapists experience and reflect on the process of developing a helpful relationship?

\section{Method}

This study is part of a larger collaborative research program examining constructive psychotherapy processes (Råbu et al. 2013) from the perspective of both the therapist (Bernhardt et al. 2019) and the client. Researcher reflexivity is paramount to qualitative research, implemented in depth in the current project (Råbu et al. 2019). To ensure methodological integrity we used a phenomenological and hermeneutical approach that supported our research goal of getting close to the participants' lived experiences (Binder et al. 2012; Van Manen 1997, 2014).

\section{Procedure for Data Collection}

We asked the leaders of nine public outpatient clinics in Norway to identify therapists they perceived to be effective in their work with most clients. In order to study helpful therapy in the context of public outpatient clinics, we asked the resulting 16 therapists to invite one client each that they had just started to work with, and that they had a hunch that they could establish a good alliance with, to take part in the study. Eleven therapists succeeded in recruiting one client. Five therapists dropped out due to changing jobs during the data collection $(\mathrm{n}=3)$, changing career $(\mathrm{N}=1)$ and facing serious illness $(n=1)$. The therapies can be characterized as "therapy as usual", adjusted by the therapists to each client's individual needs, within the context of the clinics. This context also implies that therapists most of the time are busy with a large caseloads and time strains. The therapies lasted from 6 months up to four years.

The study is based on in-depth face-to-face interviews, separately with each client and therapist. We chose a strategy with serial interviews with all participants. The intention with the serial interviews was to establish a research alliance, and a shared knowledge of the participants' personal background that could be used for understanding concrete experiences in the therapy processes that we studied. The interviews were performed by four researchers in the research group, including the two authors. All the 
interviewers have extensive experience as psychotherapists and as researchers. The interviews lasted between 60 and $90 \mathrm{~min}$, and they were conducted during a time span of 1 to 4 years.

The interview protocol was based on analysis of issues identified within existing literature, and our familiarity with the topic areas. Interviews were semi-structured and designed to enable participants to reflect on various aspects of their personal and professional experiences. The interviews were performed as open dialogues, to make it possible to follow up on issues of importance for the participants.

First, therapists were interviewed twice about their own personal development and their views on therapy. Examples of questions from the first interview with therapists were: In addition to everything you have learned about therapy, which of your personal qualities are important in your work as a therapist? What are your thoughts about what therapy can contribute to of change and development for clients? The second interview was based on a preliminary analysis of the first interview, tailored to each participant.

After the inclusion of a client, the therapist was interviewed again two more times about this specific ongoing therapy process. Examples of questions asked to the therapists about the specific therapy process were: How will you describe your relationship with this client? Do you think this therapy helped the client? In what way? What do you think have worked positively in this therapy? What may have been a hindrance? Were there any special challenges? Did anything unexpected happen? Has this client triggered any special reaction in you? (Feelings, thoughts, behavior).

The clients were interviewed twice, first about their own personal life and development, and later about their experiences in the specific therapy process with the present therapist. Examples of questions asked to the clients were: If you should give a short description of what has characterized your therapy process, what would you say? How would you describe yourself when you started therapy? Do you think the therapy has helped you? If so, what was it that helped? How is/was your relationship to the therapist like? Did it change during the process? Did she/he become an important person to you? Which of your personal characteristics made it possible for you to use this therapy? Have any of your personal characteristics been an obstacle? Was there anything you were dissatisfied with?

The interviewers used the interview guide as a starting point for an open dialog with the participants, in which they were encouraged to provide concrete narratives and examples. The order and formulations of the questions were handled in a flexible way, but the interviewer made sure that all questions were covered. The interviews were audio-recorded and transcribed verbatim.

We intended to conduct one interview during therapy and another interview after therapy. Due to practical circumstances (busy time schedules for all the involved, geographical distance), both interviews were performed after the therapy had finished in six cases. In these cases, only one interview with the client was conducted, and the interview focused both on personal development and the specific therapy process.

For the purpose of the present study, we analyzed the interviews with clients and therapists about their shared therapy process and we used the first interviews about personal development as context and background.

\section{Participants}

\section{Therapists}

The 11 therapists included four men and seven women. Their ages ranged from 37 to 60 years (mode 45 , median 41). One was a psychiatrist, while 10 were clinical psychologists. Theoretical orientations were psychodynamic (7), eclectic/ integrative (3), and cognitive (1).

\section{Clients}

The clients included four men and seven women. Their ages ranged from 20 to 51 years (mode 33, median 35). According to the therapists' and the clients' own descriptions, the clients suffered from depression, anxiety, eating disorders, addiction, and problems with anger management. We did not collect their formal diagnosis, but since all were patients in public outpatient clinics, all had been formally diagnosed with a mental disorder with loss of function in need of treatment. In order to be admitted to a public mental health clinic, the mental condition and loss of function needs to be significant. The clients pay nothing, or a small fee, for the sessions. As a group, they can be described as a normal clinical population admitted to Norwegian specialist mental health care.

\section{Researchers}

The authors are one man and one woman, 41 and 50 years, respectively, both clinical psychologists and clinical researchers, with teaching assignments and ongoing clinical practice. They share an interest in qualitative research into processes of change in psychotherapy and have backgrounds in relational, psychodynamic, emotion-focused psychotherapy, and in psychotherapy integration.

\section{Ethics}

The study was approved by the Regional Committee for Medical and Health Research Ethics (Region South-East, ref. 2012/800b) and the Norwegian Social Science Data 
Service. Identifying details such as names and places were omitted from the transcriptions and details of the participants have been changed to provide anonymity.

\section{Analysis}

The interviews were transcribed verbatim. First, each author read through the material to develop a basic sense of the overall content. Second, both authors separately carried out initial segmenting and coding, identifying potentially significant descriptions. Third, the themes were explored and critically reviewed and revised during several meetings over an 18-month period. In these meetings, we also listened to audio recordings of complete interviews to get a closer sense of the emotions and nuances in the material. Fourth, condensed descriptions were developed based on the iterative process in the third stage.

We present the findings as a phenomenological description (Dahlberg et al. 2008; Van Manen 2014), meaning that we try to catch and describe the essential meanings of the clients' and therapists' lived experiences of their therapy process. For the sake of simplicity and anonymity, we have chosen to use masculine pronouns for clients, and feminine pronouns for therapists.

\section{Results}

\section{Engaging Each Other}

First, we introduce the general narrative, identified as "engaging each other," which concisely describes the findings' most invariant meaning and is at the most abstract level of analysis. Most of the clients and all the therapists spontaneously compared their present therapy process with other and less engaging and useful therapies. The clients compared this therapist with other therapists that had been less helpful, and the therapists compared this client with other clients that had been more difficult to work with. On the most abstract level, the participants underscored how they felt engaged with each other, and by each other. Participants often used words such as "a good match" or a "safe relationship" to describe this sense of engagement from both sides. In analyzing this overarching phenomenon, three constituent processes emerged, which we detail in the following. Each description is illustrated by one exemplary quote. Each of the constituents contains two complementary perspectives from the client and from the therapist.

\section{Two Persons Opening up to an Encounter Between Humans}

Clients' Experiences The clients approached therapy with a sense of apprehension. They felt unclear about what was expected and what to expect from the therapist. Quite a few clients reported experiencing the therapist as a little scary in the beginning. Would this situation be one in which the client was to recount the expression of his suffering and receive learning and advice from a professional? What were the degrees of freedom in just being oneself? Worrying questions and some relational and role anxiety followed the clients to the initial meetings, and they felt that these questions could not be explicitly addressed. Implicitly, the clients searched for and found answers in the therapist's way of being present and how she carried herself in the sessions. The therapists made a good impression from the start. Several clients described that they felt the therapist showed a genuine wish to get to know the person of the client beyond his presenting problem.

Most clients reported judging from early on that the therapist was a good person rather than just good at her job role. To inform and trust this judgment, the clients were highly attentive to the therapist's eyes, facial expressions, breath, and posture. Sensing interest and presence from the therapist was described by many of the clients as a new experience, sometimes scary, but a sense that realized the promise that the therapist was genuinely interested in helping. The anxiety that the therapist would be somebody just "doing her job," that the clients reported would have been shameful, softened with growing experience with their concrete therapist, even if the clients knew well that their therapist treated lots of clients. Because the therapists stayed close, did not look at her watch or divert her attention, clients reported they did not feel like just one in a row and a feeling that the therapist really believed in the client grew.

I felt that she listened to me, and very clearly showed real interest in me. The eye contact, her calm way of being, plus that she shared some bits of personal stories. She told me something about perhaps her own challenges. In my own work, I am not supposed to disclose anything personal. She as a therapist should not tell much about herself. And it was not much. But that she let me know small tiny pieces of her own experiences sometimes, that was enough to create a close relationship. It was just very small pieces of something personal. It was enough to touch me and engage something deeply emotional in me.

Some clients explained that they experienced that the therapist wanted it to be a human relationship, and not just talk about symptoms. This allowed the clients to do something they rarely did and that they felt nervous doing. They got the courage to let their guard down and share experiences that 
felt shameful or difficult, letting words come more freely and spending less energy on explaining defensively so as not to be misunderstood. Most of the clients had previous therapy experiences that they could contrast this process with. In previous therapies, some of the clients explained that they had remained feeling unsafe and more closed up. The novelty of this new experience made them feel more courageous and more engaged.

Therapists' Experiences The therapists all reported to have a strong professional commitment to the sessions with clients, with particular areas in the field of clinical psychology and psychotherapy traditions that they felt professionally attracted to. Mostly, professional theory was experienced as indispensable. However, sometimes theoretical perspectives represented a challenge in the relationship with clients, for instance to get a client to understand how important it can be to get in contact with emotions. On a personal level, the therapists carried experiences from their upbringing and current personal experiences that guided their presence. From early on, they said they had felt curious about what was going on inside other people, and that they felt that they also carried wounds and losses that they to a varying degree had found ways to live with. Complex past experiences seemed to most often be experienced as resources to draw on in meetings with clients.

There was a very deep connection between us, like a common experience of the world, which provided a common ground. With him, I could be very personal. Not that he knows anything about my family, not on that level, but I could be a very personal human being with him. I try to think about the difference between him and other clients, where I can use myself, but where I never would have dared to be open, honest, and vulnerable to such a degree. I felt safe and able to be spontaneous with him. It felt good.

Therapists explained that what the clients told sometimes resonated with them and touched them emotionally. This emotional impact gave a sense of meaning to the work, allowing the therapists to try to offer a relationship of genuine interest that the therapist herself recognized that had, or would have, helped her in facing difficult feelings. It also brought a sense of boldness to the encounter with clients, as the therapists found they needed to keep balancing being present with themselves with the need to provide the clients with the space they needed.

\section{Two Perspectives on Trusting Professionalism}

Clients' Experiences Clients reported feeling apprehensive about whether the therapist would be able to provide any help with their trouble. One important issue for the clients was to feel safe, which became possible because the therapists appeared as knowledgeable professionals whom they could trust. They got the sound impression that their therapist knew what she was doing.

She was like a very "aggressive" therapist, not angry, but in the way that she went straight to the essence. Directly to the bull's eye every session, and it was hard. And I was so full of trapped sadness and anger that I had to show. It was very exhausting, but I felt... Either I felt much better after the sessions, or I felt much worse. It was a rather heavy treatment, since it was so intensive. She told me in the beginning, or during the second or third session, that "I know I might seem a little aggressive, but we are short of time, that is why I work this way." And it was fine with me. I like to get things done, so far, and she was a person who liked to get things done. It was good to know that we did it for a purpose. We worked on something important every session.

The therapists asked questions that might be challenging, and perhaps made them cry, if the therapist for instance went to the most vulnerable point and addressed feelings. Some clients had not cried in front of another person since they were children. In therapy, the clients could practice being sad, and the therapist helped them to pull themselves together toward the end of the session when they needed that. They could dare to cry and felt safe that the therapist would help them so they would not continue to cry forever, which for some had been a fear. The clients experienced that they had work to do, and that they worked well together with the therapist.

In many cases the present therapist was experienced as contrasting with previous therapists. Previous therapists had provided some good advice, but the clients did not really trust them and could not dare to open up. The clients' found that the present therapist worked systematically to find out how far she could go when it came to the issues they needed to challenge. They experienced it as if the therapist was able to judge how much the client could bear, and the clients typically felt that they were now ready for it. The clients appreciated that the therapist recognized that they were not only vulnerable, but also solid enough to be challenged, and that they could endure it. The clients felt that they got a more objective view on how one can talk about one's own life: "We did not have unlimited time, so we had to get the work done." Even if the clients knew the therapist was using a therapeutic method, it felt good, and it helped. One client who felt that the therapist was using a method and not always being that genuine, experienced it as helpful anyway, and longed for more. 
Therapists' Experiences Several of the therapists reported that they were impressed by their clients' willingness to challenge themselves and to make changes in their life. The therapists also tried to help the clients to regulate their emotions. The therapists were careful to explain what they were doing and what they tried to accomplish together with the client. They used meta-communication to continuously give the client a rationale for what they were doing. Some therapists experienced their client as very scared and fragile in the beginning, but anyway trustful from the start. The therapists said they were careful to help the client to prepare for upcoming situations that could be challenging.

Sometimes I feel the risk of letting the contact become solely intellectual. One can do therapy that way, fair enough, but I think it is less effective than if you actualize attachment needs and challenge emotions. What is happening here and now, and how does it feel? You need to take risks. The intellectual track is very much the comfort zone, to just sit there and think together with the patient, to just provide some comment on what he says. To only be the quiet container feels too static: To be the receiver, the listener, to keep the frames. It feels better when I dare to be more spontaneous, and I even feel safe when I do it. It is necessary to take active part in the relationship and contribute to make it more dynamic. And you never know exactly what is going to happen, you need to trust the process.

To demonstrate to clients that power need not be conceded to the objects of clients' fears, the therapists spoke openly about those fears. Several of the therapists also told in the interviews about how they needed to challenge themselves. It was important to both parties that they had work to do, and therefore needed to challenge both oneself and the other.

\section{Through Mutual Engagement Emerged a Space for an Unbearable Story}

Clients' Experiences Some of the clients told about how they felt miserable in the beginning, and overwhelmed and lost in their troubles. They had hidden away from everyone, and for example tried to completely forget what had happened in their childhood, and several other painful experiences were swept under the carpet. They reported believing that they could not bother others with their unbearable troubles. In that sense, it had remained hidden and private, and not symbolized and given expression in a relationship. What they had experienced, they explained in the interviews, was something they believed was impossible to talk about among other people. They felt full of shame and estranged and did not want people to know about these experiences. As they expressed, it felt as something too private, and they struggled both to hide it away and at the same time felt a desperate urge to talk with someone about it. They had suffered much when they had dealt with it on their own for many years.

To go through this therapy with the therapist was a feeling of passing through a very scary room, but I had someone there who "held my hand," and, okay, we might encounter a monster, but we are two together, I am not alone. It was an enormous relief to be able to walk into that room, and it was hard, and I have suffered through the whole process, but it was a wonderful experience, a few weeks ago, to be able to talk about it as if it had happened in another life almost.

Eventually, the clients became able to tell the grim and embarrassing story as it was, without too much tidying up. After this therapy, the clients reported that they got a very strong faith in therapy, and in the power of being able to put unbearable experiences into words together with another person. They felt that they had got a more "objective" view on how one could tell about oneself, and the sharing of an unbearable story instigated a feeling of being less alone.

Therapists' Experiences To keep an openness to what the clients may have to tell, and in addition listen behind the words, seemed to be important. The therapists needed to listen carefully for the almost unbearable story of vulnerability and not jump to conclusions.

I had a hunch that his eating disorder had something to do with intimacy, and a story about falling in love for the first time. He had opened up toward the person he was in love with and experienced being rejected and hurt. He had a story of being silent and to some degree ignored by his family, and anorexia almost killed him. He probably became irritated with me because I was so persistent about that first love story. Others would probably have left it, accepted his claim that it was a bagatelle. But I felt that this story, which he hardly told me, was an important one. I did not forget about it. It hit me so hard. I felt it came from his heart, even if he tried to make it a bagatelle. It was demanding, he wanted to forget about it, but I felt it was important, and it turned out to be.

Often it took time for a client to be ready to tell their most hurtful or embarrassing story, to dare to do it, and sometimes it also took time to allow it to be significant.

\section{Discussion}

We have studied the dyadic experiences in 11 psychotherapy processes with a particular focus on the development of the relationship. Findings illustrate how participants in 
the psychotherapy process relate to each other as fellow humans and that they engage in symbolic interaction with the intent to heal (Wampold 2007). Exploring the research question about how clients and therapists develop a relationship that the client can use to develop, grow or heal, we have described this as a process of mutual engagement. Through the constituents underlying this engagement process, we described how clients open up to the therapist, and, conversely, how therapists felt personally engaged by clients' stories. Furthermore, we described how this interpersonal engagement seemed to follow from a shared trust in professionality, in which safety was developed in dialog with process knowledge and robustness from the therapist's side. Finally, we discussed the result of the mutual engagement, in that experiences, often not shared with anyone, could be symbolized and shared between the two persons in the room.

Adhering to the aim to operationalize constructs, the empirical psychotherapy research tradition has often separated technical aspects from relational or personal aspects within the therapeutic process. For example, in a qualitative meta-analysis of client therapy experiences, Levitt et al. (2016) reported two resulting clusters addressing how caring and acceptance underlie engagement and self-awareness, whereas professional structure allows for credibility. Moreover, in primary studies, McElvaney and Timulak (2013), qualitatively studying good and poor outcome processes from the client perspectives, reported that those with poorer outcomes did not manage to fully engage with the therapist. In the adult client population, Binder et al. (2009) reported from a study establishing that clients needed a relationship with a therapist described as warm, wise, and competent, mirroring a duality between open interpersonal engagement regulated by trust in professionality. Similarly, Littauer et al. (2005) reported that clients needed therapists to have a confident plan and that it was vital that they expressed acceptance. As a final example, Lavik et al. (2018b) studied adolescents' psychotherapy needs and reported needs for the therapists to (a) be warm, invested, and emotionally engaged; (b) offer company and presence as a real human being; and (c) have integrity as an adult and a professional.

In the clinical situation, however, technique and relationship are not separate entities in a dichotomy. As one example from a qualitative meta-analysis, the need to understand technical skill and personal warmth in combination is paramount, both from therapist nor client perspectives (Lavik et al. 2018a, b). The relational tradition in psychoanalysis provides what perhaps is the most developed theoretical formulation for understanding therapeutic encounters holistically, rather than compartmentally. In particular, Benjamin's (2018) work on the dynamics of complementarity and intersubjectivity synthesize insights from both the therapeutic (Stolorow and Atwood 1992) and the caregiver-infant relationship (Beebe and Lachmann 2005). In this synthesis, a dichotomy between technique and relationship seems unnecessarily superficial, as relational dynamics of mutual recognition or destruction holds stronger explanatory power for what transpires in a therapeutic relationship. For example, the example in the results from a client who experienced the therapist as partly inauthentic in using a technique instrumentally, but who accepted this while longing for more, cannot be understood by empirical dichotomies between technique and relationship. Relational clinical theories, however, can contribute nuanced language for such processes.

Between empirical studies implicitly communicating a dichotomy by describing the vital combination of professionality and personal warmth and acceptance, and relational theory with a nuanced language for intersubjective processes, how can this dyadic narrative analysis contribute? First, in retrospective single-perspective studies participant can establish that something was an important need, but less about how this need was mutually shared and played out in interaction throughout the actual process. In the overarching description and the three constituents, a process unfolds in the current study. Second, initial preverbal ways of being together, with a strong focus on bodily expressed care, acceptance, and personal presence of the therapist emerges to be important groundwork but not the end point. Here, the results from the current study can inform and bring life to relational theory accounts, from the processes where the therapist is allowed to be a witness to the client's unbearable story (Speedy 2004).

Gelso (2005) addressed this phased reality of psychotherapy and suggested that, within the construct of the real relationship, the magnitude of realism, that the other is perceived in a way that fits her, was particularly important in the beginning and end of therapy. In everyday language, in starting and ending a therapy process the realistic appraisal of who the therapist is seems more important than in the middle working phase, where the professional role is more in the front. This insight is mirrored in the first dyadic descriptions, where the perception of who the other is seemed paramount to the encounter.

We find this interesting, and important, in light of Miller's (2004, 2005) insight that psychotherapy and witnessing and engaging in suffering is, inevitably, a practice within the realm of morality. Miller (2005) paints a vivid picture of clients who

...come to us speaking the language of moral injury. They are demoralized: confused as to what direction to go in life $[\ldots]$ feeling abandoned in love $[\ldots]$ humiliated by their station in life [...] They hope we will help them restore their morale - that is, both their belief that the world and life can be a good place for them (again) and their faith in the goodness of humanity or themselves (p. 301). 
From the clients' perspective, if we do accept that Miller's description at least partly reflects their experiences, or at least reflects some clients' experiences, their choice whether to open up to an encounter with one's suffering is a question of the therapist's morality, to be found in her personhood, rather than just her role performance. Seeing psychotherapy as encounters within the realm of morality might add a necessary framework for understanding results from the empirical research tradition examining the therapist factor. For example, therapist humility (Nissen-Lie et al. 2017), honesty, respectfulness and trustworthiness (Ackerman and Hilsenroth 2003), relationality (Nissen-Lie et al. 2013), and vulnerability (Bernhard et al. 2018), are all linked to helpful therapeutic presence. Such findings can meaningfully be understood as communicating moral trustworthiness to clients. The present study describes processes where such qualities support the development of mutual engagement toward symbolic sharing of suffering.

\section{Limitations}

As all other research studies, this one was carried out in a particular context, which in this case is a small Scandinavian country where mental health care is publicly funded. Of the 16 participating therapists in the main research program, only 11 managed to recruit a client for the study. We intended to study helpful therapy processes, and therapists were asked to invite clients whom they believed they could create a positive relationship with, whereupon we explored this engaging relationship. This study is therefore a somewhat circular study of a limited group of therapists and clients that were engaged and courageous enough to participate in this quite time-consuming study. Only two researchers took part in the analytic process. We have chosen a thorough way of analyzing the material through listening to sound recordings, reading transcripts, and discussing the meaning of it. However, more researchers could have contributed to other understandings. The presenting of our findings intends to convey the complexity of human emotional experience and meaning-making. A more schematic presentation could have been more transparent.

Acknowledgements Open Access funding provided by University of Oslo (incl Oslo University Hospital).

Open Access This article is licensed under a Creative Commons Attribution 4.0 International License, which permits use, sharing, adaptation, distribution and reproduction in any medium or format, as long as you give appropriate credit to the original author(s) and the source, provide a link to the Creative Commons licence, and indicate if changes were made. The images or other third party material in this article are included in the article's Creative Commons licence, unless indicated otherwise in a credit line to the material. If material is not included in the article's Creative Commons licence and your intended use is not permitted by statutory regulation or exceeds the permitted use, you will need to obtain permission directly from the copyright holder. To view a copy of this licence, visit http://creativecommons.org/licenses/by/4.0/.

\section{References}

Ackerman, S. J., \& Hilsenroth, M. J. (2003). A review of therapist characteristics and techniques positively impacting the therapeutic alliance. Clinical Psychological Review, 23, 1-33. https://doi. org/10.1016/S0272-7358(020146-0.

Anderson, T., Ogles, B. M., Patterson, C. L., Lambert, M. J., \& Vermeersch, D. A. (2009). Therapist effects: Facilitative interpersonal skills as a predictor of therapist success. Journal of Clinical Psychology, 65, 755-768.

Baldwin, S. A., \& Imel, Z. E. (2013). Therapist effects: Findings and methods. In M. J. Lambert (Ed.), Bergin and Garfield's handbook of psychotherapy and behavior change (Vol. 6, pp. 258-297). New York, NY: Wiley.

Beebe, B., \& Lachmann, F. M. (2005). Infant Research and Adult Treatment. Co-constructing interactions. Hillsdale, NJ: Analytic Press.

Benjamin, J. (2018). Beyond doer and done to. Recognition theory, intersubjectivity and the third. New York: Routledge.

Bernhardt, I. S., Nissen-Lie, H. A., Moltu, C., McLeod, J., \& Råbu, M. (2019). It's both a strength and a drawback. How therapists' personal qualities are experienced in their professional work. Psychotherapy Research, 29, 959-970.

Binder, P. E., Holgersen, H., \& Moltu, C. (2012). Staying close and reflexive: An explorative and reflexive approach to qualitative research on psychotherapy. Nordic Psychology, 64(2), 103-116.

Binder, P. E., Holgersen, H., \& Nielsen, G. H. (2009). Why did I change when I went to therapy? A qualitative analysis of former patients' conceptions of successful psychotherapy. Counselling and Psychotherapy Research, 9, 250-256.

Bordin, E. (1979). The generalizability of the psychoanalytic concept of the working alliance. Psychotherapy: Theory, Research, 16(3), 252.

Dahlberg, K., Nyström, M., \& Dahlberg, H. (2008). Reflective lifeworld research. Lund: Studentlitteratur.

Duncan, B. (2014). On becoming a better therapist. Washington, DC: APA.

Freud, S. (1937). Analysis terminable and interminable Standard Edition, vol. 23. In J. Strachey (Ed.), Standard edition of the complete works of Sigmund Freud. London: Hogarth Press.

Gelso, C. J. (2009). The real relationship in a postmodern world: Theoretical and empirical explorations. Psychotherapy Research, 19(3), 253-264.

Gelso, C. J. (2011). The real relationship in psychotherapy: The hidden foundation of change. Washington, DC: American Psychological Association.

Gelso, C. J. (2014). A tripartite model of the therapeutic relationship: Theory, research, and practice. Psychotherapy Research, 24(2), 117-131.

Gelso, C. J., Kivlighan, D. M., Jr., \& Markin, R. D. (2018a). The real relationship and its role in psychotherapy outcome: A meta-analysis. Psychotherapy, 55(4), 434-444. https://doi.org/10.1037/pst00 00183.

Gelso, C. J., Kivlighan, D. M., \& Markin, R. D. (2018b). The real relationship. In J. C. Norcross \& M. J. Lambert (Eds.), Psychotherapy relationships that work (3rd ed.). New York, NY: Oxford University Press.

Halvorsen, M. S., Benum, K., Haavind, H., \& McLeod, J. (2016). A life-saving therapy: The theory building case of "Cora". Pragmatic Case Studies in Psychotherapy, 12(3), 158-193.

Hill, C. E., Knox, S., \& Pinto-Coelho, K. G. (2018). Therapist self-disclosure and immediacy: A qualitative meta-analysis. 
Psychotherapy, 55(4), 445-460. https://doi.org/10.1037/pst00 00182.

Johns, R. G., Barkham, M., Kellett, S., \& Saxon, D. (2019). A systematic review of therapist effects: A critical narrative update and refinement to Baldwin and Imel's (2013) review. Clinical Psychology Review, 67, 78-93.

Kraus, D. R., Castonguay, L. G., Boswell, J. F., Nordberg, S. S., \& Hayes, J. A. (2011). Therapist effectiveness: Implication for accountability and patient care. Psychotherapy Research, 21, 267-276.

Lavik, K. O., Frøysa, H., Brattebø, K. F., McLeod, J., \& Moltu, C. (2018a). The first sessions of psychotherapy: A qualitative metaanalysis of alliance formation processes. Journal of Psychotherapy Integration, 28(3), 348-366. https://doi.org/10.1037/int0000101.

Lavik, K. O., Veseth, M., Frøysa, H., Binder, P. E., \& Moltu, C. (2018b). 'Nobody else can lead your life': What adolescents need from psychotherapists in change processes. Counselling Psychotherapy Research, 18(3), 262-273.

Levitt, H. M., Andrew, P., \& Francisco, I. S. (2016). A qualitative metaanalysis examining clients' experiences of psychotherapy: A new agenda. Psychological Bulletin, 142(8), 801.

Littauer, H., Sexton, H., \& Wynn, R. (2005). Qualities clients wish for in their therapists. Scandinavian Journal of Caring Sciences, 19(1), 28-31.

McElvaney, J., \& Timulak, L. (2013). Clients' experience of therapy and its outcomes in 'good' and 'poor' outcome psychological therapy in a primary care setting: An exploratory study. Counselling and Psychotherapy Research, 13(4), 246-253.

Miller, R. B. (2004). Facing human suffering: Psychology and psychotherapy as moral engagement. Washington, DC: American Psychological Association.

Miller, R. B. (2005). Suffering in psychology: The demoralization of psychotherapeutic practice. Journal of Psychotherapy Integration, 15(3), 299-336. https://doi.org/10.1037/1053-0479.15.3.299.

Moltu, C., Binder, P. E., \& Nielsen, G. H. (2010). Commitment under pressure. Experienced therapists' inner work during difficult therapeutic impasses. Psychotherapy Research, 20, 309-320. https:// doi.org/10.1080/1050330903470610.

Moltu, C., Binder, P. E., \& Stige, B. (2012). Collaborating with the client in the struggle toward growth: Skilled psychotherapists' experiences of the patient in difficult therapies ending well. Journal of Psychotherapy Integration, 22(2), 85-108. https://doi. org/10.1037/a0028010.

Nissen-Lie, H. A., Monsen, J. T., Ulleberg, P., \& Rønnestad, M. H. (2013). Psychotherapists' self-reports of their interpersonal functioning and difficulties in practice as predictors of patient outcome. Psychotherapy Research, 23(1), 86-104.

Nissen-Lie, H. A., Rønnestad, M. H., Høglend, P. A., Havik, O. E., Solbakken, O. A., Stiles, T. C., et al. (2017). Love yourself as a person, doubt yourself as a therapist? Clinical Psychology and Psychotherapy, 24(1), 48-60. https://doi.org/10.1002/cpp.1977.
Okiishi, J., Lambert, M. J., Nielsen, S. L., \& Ogles, B. M. (2003). Waiting for supershrink: An empirical analysis of therapist effects. Clinical Psychology and Psychotherapy, 10, 361-373.

Rennie, D. L. (2000). Aspects of the client's conscious control of the psychotherapeutic process. Journal of Psychotherapy Integration, 10, 151-167.

Rhodes, R. H., Hill, C. E., Thompson, B. J., \& Elliott, R. (1994). Client retrospective recall of resolved and unresolved misunderstanding events. Journal of Counseling Psychology, 41, 473-483.

Råbu, M., Halvorsen, M. S., \& Haavind, H. (2011). Early relationship struggles: A case study of alliance formation and reparation. Counselling and Psychotherapy Research, 11, 23-33.

Råbu, M., Hytten, K., Haavind, H., \& Binder, P. E. (2010). Development through interruptions and reparations-A case study of a mutually challenging psychotherapy. European Journal of Psychotherapy and Counselling, 12, 287-302.

Råbu, M., McLeod, J., Haavind, H., Bernhardt, I. S., Nissen-Lie, H. A., \& Moltu, C. (2019). How psychotherapists make use of their experiences from being a patient: Lessons from a collective autoethnography. Counselling Psychology Quarterly. https://doi. org/10.1080/09515070.2019.1671319.

Rabu, M., Moltu, C., \& McLeod, J. (2013). The art and science of conducting psychotherapy: How collaborative action between client and therapist generates and sustains productive life change. Oslo: University of Oslo, Department of Psychology.

Soldz, S. (2006). Models and meanings: Therapist effects and the stories we tell. Psychotherapy Research, 16, 173-177.

Speedy, J. (2004). Living a more peopled life: Definitional ceremony as inquiry into psychotherapy 'outcomes'. International Journal of Narrative Therapy \& Community Work, 2004(3), 43-53.

Stolorow, R., \& Atwood, G. (1992). Contexts of being: The intersubjective foundations of psychological life. Hillsdale NJ: Analytic Press.

Tallman, K., \& Bohart, A. C. (1999). The client as a common factor: Clients as self healers. In M. A. Hubble, B. L. Duncan, \& S. D. Miller (Eds.), The heart \& soul of change. What works in therapy. Washington, DC: American Psychological Association.

Van Manen, M. (1997). Researching lived experience: Human science for an action sensitive pedagogy. Ontario: Althouse Press.

Van Manen, M. (2014). Phenomenology of practice. Walnut Creek, CA: Left Coast Press.

Wampold, B. (2007). Psychotherapy: The humanistic (and effective) treatment. American Psychologist, 62, 857-873.

Publisher's Note Springer Nature remains neutral with regard to jurisdictional claims in published maps and institutional affiliations. 